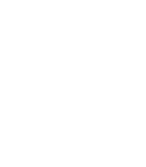

\section{${ }_{\text {REVIEWS }}^{\text {ANUAL Further }}$}

Click here for quick links to Annual Reviews content online, including:

- Other articles in this volume

- Top cited articles

- Top downloaded articles

- Our comprehensive search

\title{
The Diagnosis of Mental Disorders: The Problem of Reification
}

\author{
Steven E. Hyman \\ Department of Neurobiology, Harvard Medical School, Harvard University, Cambridge, \\ Massachusetts 02138; email: seh@harvard.edu
}

Annu. Rev. Clin. Psychol. 2010. 6:155-79

First published online as a Review in Advance on January 4, 2010

The Annual Review of Clinical Psychology is online at clinpsy.annualreviews.org

This article's doi:

10.1146/annurev.clinpsy.3.022806.091532

Copyright (c) 2010 by Annual Reviews. All rights reserved

$1548-5943 / 10 / 0427-0155 \$ 20.00$

\section{Key Words}

DSM-V, ICD-11, validity, dimension

\begin{abstract}
A pressing need for interrater reliability in the diagnosis of mental disorders emerged during the mid-twentieth century, prompted in part by the development of diverse new treatments. The Diagnostic and Statistical Manual of Mental Disorders (DSM), third edition answered this need by introducing operationalized diagnostic criteria that were field-tested for interrater reliability. Unfortunately, the focus on reliability came at a time when the scientific understanding of mental disorders was embryonic and could not yield valid disease definitions. Based on accreting problems with the current DSM-fourth edition (DSM-IV) classification, it is apparent that validity will not be achieved simply by refining criteria for existing disorders or by the addition of new disorders. Yet DSM-IV diagnostic criteria dominate thinking about mental disorders in clinical practice, research, treatment development, and law. As a result, the modern DSM system, intended to create a shared language, also creates epistemic blinders that impede progress toward valid diagnoses. Insights that are beginning to emerge from psychology, neuroscience, and genetics suggest possible strategies for moving forward.
\end{abstract}




\section{Contents}

INTRODUCTION ............... 156

THE BENEFITS AND COSTS

OF PRIORITIZING

INTERRATER RELIABILITY . . . 159

CLASSIFICATION ............... 160

THE INTELLECTUAL BASIS

OF DSM-III ................ 162

THE LIMITATIONS OF

CATEGORICAL DIAGNOSES . . 163

THE PROBLEM OF

OVERSPECIFICATION ......... 166

THE PROBLEM OF

COMORBIDITY 167

FAMILY AND GENETIC DATA

DO NOT CONFIRM DSM-IV

DISORDER BOUNDARIES ..... 169

WHAT IS TO BE DONE? ......... 171

Disorder: generally used to describe a medical condition or abnormality conferring harm or risk of harm in which etiology or pathologic processes are unknown

Classification: an organizing structure imposed on data to achieve a specific purpose. No classification is perfect or without

controversy, not even the classification of living organisms that dates from Linnaeus

Disease: generally used to describe a medical condition or abnormality conferring harm or risk of harm in which etiology or pathologic processes (pathophysiology) are known

\section{INTRODUCTION}

The tendency has always been strong to believe that whatever received a name must be an entity or being, having an independent existence of its own.

John Stuart Mill

This is an important time to reflect on the state of diagnosis for mental disorders, as both the Diagnostic and Statistical Manual of Mental Disorders, fourth edition (DSM-IV; Am. Psychiatr. Assoc. 1994) and the International Classification of Diseases, tenth edition (ICD-10, World Health Org. 1992), Chapter V, Mental and Behavioural Disorders, are being revised in preparation for DSM-V and the ICD-11. These revision processes face complex competing demands. On the one hand, it is critical that these classifications be open and responsive to new discoveries just beginning to emerge from psychology, neuroscience, and genetics else progress toward valid disease definitions will not occur. On the other hand, alterations in the criteria for existing disorders may undercut existing bodies of research, such as apparent prevalence (Crino et al. 2005) and, to some degree, the applicability of existing clinical trials data. More substantial changes to criteria may force alterations in patterns of clinical practice and disrupt the large array of administrative uses to which the classification manuals are put.

The DSM-IV (Am. Psychiatr. Assoc. 1994) and the closely related ICD-10 (World Health Org. 1992) organize the universe of mental disorders. The disorders contained therein are heuristics that have proven extremely useful in clinical practice and research, especially by creating a common language that can be applied with reasonably good interrater reliability. Unfortunately, the disorders within these classifications are not generally treated as heuristic, but to a great degree have become reified. Disorders within the DSM-IV or ICD-10 are often treated as if they were natural kinds, real entities that exist independently of any particular rater (Kendell \& Jablensky 2003). In research, for example, DSM-IV criteria must be used in order to satisfy most grant-making bodies, journal reviewers and editors, and organizers of scientific meetings. In the clinic, DSM-IV diagnoses influence treatment choice and determine eligibility for reimbursement. DSM-IV diagnoses are taught to trainees in psychology, psychiatry, and other fields, and are often memorized for certification examinations. It is rare for alternative diagnostic approaches to be tested (see sidebar Autobiographical Notes from a Reluctant Nosologist; Hyman \& Fenton 2003). Moreover, there are significant conceptual and regulatory stumbling blocks in the way of developing treatments for conditions that do not match the criterion lists contained within the DSM-IV. This is illustrated by the regulatory challenges that had to be met in order to develop treatments for the cognitive deficits that are characteristic of schizophrenia.

Despite the success of both first- and second-generation antipsychotic drugs for treatment of the hallucinations and delusions (positive symptoms) of schizophrenia, individuals with this illness remain significantly disabled. Much of the treatment-refractory 
disability of schizophrenia had been shown to result from cognitive deficits (Green 1996). These reflect abnormal functioning of the prefrontal cerebral cortex, resulting in impairment of working memory and thus the ability to control thought and behavior in conformity with internally represented goals (Bowie et al. 2006, Cannon et al. 2002, Tan et al. 2006). As was already apparent, albeit only documented later in a large trial (Keefe et al. 2007), existing treatments had only modest therapeutic effects on cognitive symptoms of schizophrenia. Thus, in the late 1990s it seemed important, as a public health matter, for the National Institute of Mental Health (NIMH) to encourage relevant therapeutic research (Hyman \& Fenton 2003).

At first it seemed odd that the pharmaceutical industry and its academic partners had not already undertaken a significant effort to address cognitive symptoms of schizophrenia, but it soon became clear that this was not a simple matter. The hurdles were not only scientific-in fact, useful scientific leads already existed-but also included the role of the DSM-IV (Am. Psychiatr. Assoc. 1994) in determining what could constitute an appropriate indication for treatment development. The DSM-IV makes no mention of the cognitive symptoms of schizophrenia because the criteria were based on older conceptions that focused largely on positive symptoms and noncognitive negative symptoms. Given the status of the DSM-IV criteria as the community consensus, the U.S. Food and Drug Administration (FDA) held that it could not, by itself, recognize the cognitive symptoms of schizophrenia as an indication for the development and approval of new treatments. Thus, it took a series of special meetings convened by the NIMH and FDA, academia, and the pharmaceutical industry to create a process that would lead to the recognition of the cognitive symptoms of schizophrenia as a valid indication (Buchanan et al. 2005). The existence of this hurdle highlights the regulatory role of the DSM-IV and therefore the need to improve the validity of the system.

The current classification also exerts a significant influence beyond the clinic and the

\section{AUTOBIOGRAPHICAL NOTES FROM A RELUCTANT NOSOLOGIST}

To me, nosology seemed a bit like stamp collecting, an absorbing activity perhaps, but not a vibrant area of inquiry. During my period as director of the National Institute of Mental Health (NIMH) from 1996-2001, I came to realize, however, that the DSM-III-R (Am. Psychiatr. Assoc. 1987) and its successor, the DSM-IV (Am. Psychiatr. Assoc. 1994), exerted enormous influence both for good and ill on the research funded by the Institute. The DSM system was a critical platform for research that made possible shared understandings of disease models or affected populations under study. At the same time, it created an unintended epistemic prison that was palpably impeding scientific progress. Outside of their ongoing research projects, most investigators understood that the DSM-IV was a heuristic, pending the advance of science. In practice, however, DSM-IV diagnoses controlled the research questions they could ask, and perhaps, even imagine.

The Initial Review Groups (study sections) that evaluated grant applications that came to the NIMH almost always required the use of DSM criteria in proposed scientific studies. Similarly, journals editors and referees generally required the use of these criteria in research submitted for publication. In addition, regulatory agencies, such as the U.S. Food and Drug Administration (FDA), understandably took the DSM criteria to represent the scientific community consensus on valid indications for the approval of new treatments. Even animal studies that purported to develop disease models, whether by environmental interventions or genetic engineering, were often judged by how closely they approximated DSM disorders. It became a source of real worry to me, that as Institute director, I might be signing off on the expenditure of large sums of taxpayers' money for clinical and translational projects that almost never questioned the existing diagnostic categories despite their lack of validation. Moreover, there seemed to be very little, if any, research aimed at improving this parlous situation.

My alarm was heightened when, early in my tenure, negative results were reported from several genetic linkage studies. I was baffled that many (although thankfully not all) research groups had been funded to collect only enough phenotype data to diagnose DSM-III-R (Am. Psychiatr. Assoc. 1987) or DSM-IV (Am. Psychiatr. Assoc. 1994) disorders, as if these were natural kinds that would map onto the human genome. Although in retrospect, the linkage methods of the 1990's have proven inadequate, the DSM definitions of the disorders under investigation might well have doomed these expensive projects before they started. 
The problematic effects of diagnostic reification were revealed repeatedly in genetic studies, imaging studies, clinical trials, and types of studies where the rigid, operationalized criteria of the DSM-IV defined the goals of the investigation despite the fact that they appeared to be poor mirrors of nature (Hyman 2007).

Reliability: interrater reliability means that two observers will reach the same diagnosis with high probability for a given patient examined at approximately the same time. Test-retest reliability means that the same person will receive the same diagnosis if examined at reasonably close time intervals

Validity: means that a diagnosis picks out a "natural kind" based on etiology or pathophysiology

Nosology: the branch of medical science dealing with disease classification laboratory. The most recent version of the DSM system, the Diagnostic and Statistical Manual of Mental Disorders, Fourth Edition, Text Revision (DSM-IV-TR; Am. Psychiatr. Assoc. 2000), explicitly warns that the classification is made against the background of an evolving field and that its diagnoses were not meant to control understandings outside the realms of clinical practice and research:

It is to be understood that inclusion here, for clinical and research purposes, of a diagnostic category such as Pathological Gambling or Pedophilia does not imply that the condition meets legal or other nonmedical criteria for what constitutes mental disease, mental disorder, or mental disability. (Am. Psychiatr. Assoc. 2000, p. xxxvii)

What real alternatives are available to nonclinical communities? Despite the "cautionary statement," for individuals with problem gambling or their advocates, the idea that they might have a "real" disorder that undermines self-control, might prove quite welcome. If pathological gambling is broadly accepted as a disorder, individuals with symptoms might benefit from improved access to treatment and a plausible explanation for their behavior that diminishes attributions of responsibility and thus stigma. Although others, ranging from prosecutors to insurance companies, might be skeptical of the designation as a disorder on the basis of factors ranging from established legal views of self-control (Morse 2004) to economic selfinterest, they are far less likely to question the existence of a class of pathological gamblers. Indeed, scientific and clinical communities may not question the class or the structure within which it exits.
In this review, I am not arguing against the possibility that pathological gambling represents significantly disordered behavior that might have a discoverable neural basis and that warrants treatment. I am not arguing that the world would be better off without a shared language to diagnose mental disorders. What I am arguing is that cautionary statements within the DSM-IV, if read at all, provide little protection among many communities of users against reification of the disorders listed within. For example, in the case of pathological gambling and other impulse-control disorders, it is not currently clear what a "valid" and clinically useful classification would look like. Is lumping better than breaking out every behavior that can become compulsive into a listed or candidate disorder, such as gambling, shopping, Internet use, or sexual activity? Would research results make more sense and clinical care be improved if a classification lumped goal-directed behaviors characterized by significant loss of control? Would it ultimately prove better to ground these diagnoses in a shared liability factor, such as a disordered interaction between mesotelencephalic brain reward circuits and prefrontal cortical circuits underlying cognitive control? How might a classification best handle the pathological gambler who is also a compulsive user of alcohol and tobacco? Does this person warrant three diagnoses, as would currently be the case? Is pathological gambling a category that is discontinuous from health, as portrayed in the DSM-IV, or does it differ from normal behavioral variation only by degree? Whether categorical or quantitative, how might defensible thresholds be set to indicate a point at which common human behavior, such as gambling or shopping, would justifiably be considered pathological and come under the purview of mental health professionals? If DSM-V and ICD-11 maintain the fundamental structure created by the DSMIII, the answers to these important open questions will be treated de facto as settled. I list these initial questions to illustrate the ease by which widely accepted systems of classification can morph into epistemic blinders that impede 
scientific progress. In the case of the DSM system and its progeny, the unintended reification of diagnostic entities is facilitated by the lack of a developed scientific base, combined with the wide embrace of a classification system developed, above all, to foster interrater reliability. The committee members (of which I am currently one) charged with revising the DSM-IV and ICD-10 thus face a paradoxical task: They must be wary of undercutting a broadly shared language with the attendant risk of leaving confusion in their wake; at the same time, they must be aware that if unchanged, this language, based on a science more than four decades old and in some cases more than a century old, will further calcify what I argue is a highly problematic status quo.

\section{THE BENEFITS AND COSTS OF PRIORITIZING INTERRATER RELIABILITY}

Given the lack of objective diagnostic tests for mental disorders, the difficulties facing both clinicians and researchers needing to agree on the diagnosis of any given patient has been a concern for at least half a century (Beck et al. 1962). The foundation of diagnostic agreement is a shared classification system that contains diagnoses that can be applied reliably, meaning that different raters can achieve diagnostic agreement a high percentage of the time.

Reliable and widely shared disease definitions are a necessary antecedent for rational treatment decisions. Diagnosis guides a clinician's thinking about treatment, about other symptoms that might be present, about likely impairments, and about prognosis. Shared and reliable diagnoses are the cornerstone of communication between the clinician and the patient and, where appropriate, with families, other caregivers, and institutions. Diagnosis is also central to translational and clinical research: Without clear diagnostic guideposts, idiosyncratic groupings confound clinical trials, epidemiology, genetics, imaging, and other laboratory studies. In their absence, academia and industry lack indications for which to develop new treatments, and regulatory agencies cannot judge efficacy. Diagnosis also plays an important role outside the clinic and laboratory, influencing, for example, insurance reimbursement, determinations of disability, school-based interventions for symptomatic children, and diverse legal proceedings.

In general medicine, the availability of objective tests and shared laboratory standards has meant that interrater reliability is often taken for granted. The lack of objective tests for mental disorders, in contrast, makes diagnostic reliability a difficult problem. Given the early state of the science, the DSM-III (Am. Psychiatr. Assoc. 1980) had to rely on phenomenology: symptoms, signs, and course of illness as the basis for diagnosis. In order to forge phenomenology into clearly applicable rules for making diagnoses, the DSM-III reduced this information to operationalized diagnostic criteria that were field tested for interrater reliability. This approach was also embraced within the ICD-9 chapter on Mental and Behavioural Disorders (World Health Org. 1977). Operationalization means that concepts are defined in terms of specific observations or measures. The observations and measures that contributed to the diagnostic criteria were selected to be readily ascertainable in clinical settings. For example, the DSM-III requires six months of continuous illness at some point in a person's life to make a diagnosis of schizophrenia (Am. Psychiatr. Assoc. 1980). However, the six-month criterion illustrates the tradeoff that occurs between specificity and arbitrariness when interrater reliability is desired but scientific information is lacking. There is no empirical basis for selecting six months as a cutoff, but it gives a kind of precision to the diagnosis of schizophrenia that it would lack if the definition simply asked that symptoms be "chronic." Indeed the ICD10 (World Health Org. 1992) requires only that one of the cardinal symptoms be present for one month or more. Both manuals have the same intentions, but such arbitrary differences in operationalization influence measurements of prevalence and selection of subjects for research and treatment.
Diagnostic criteria: rules for making diagnoses. The Diagnostic and Statistical Manual of Mental Disorders, Fourth Edition, Text Revision (1990) and ICD-10, Chapter V (Mental Disorders) provide both classifications and diagnostic criteria. Other chapters of the ICD-10 lack criteria 
The significant heterogeneity of clinical presentations presents a challenge to highly specified, operationalized definitions. In attempting to handle heterogeneity without sacrificing reliability, DSM-III (Am. Psychiatr. Assoc. 1980) made the diagnostic criteria polythetic, meaning that diagnoses can be arrived at by choosing among different combinations of specific operationalized criteria listed under a disorder. For example, the diagnosis of major depression requires that a patient meet five of the nine listed criteria for at least two weeks. Although superficially sensible, this solution does not fully capture the heterogeneous presentations of mental disorders as is discussed below. Moreover, it created a new kind of problem: Two individuals with identical diagnoses of major depression might be alike on as few as one of the nine criteria (given that five are needed to make the diagnosis), creating significant challenges for interpreting the results of research conducted on putatively homogeneous populations.

In comparison with DSM-III, its predecessor volumes DSM-I and -II were slim compendia that lacked clear guidance as to how diagnoses were to be made. DSM-I and DSM-II followed on a tradition of classifications meant largely to permit the collection of health statistics. They do not appear to have been very influential in clinical practice or research and did not have significant global influence. Thus, for example, as a result of differing approaches to diagnosis, it appeared in the 1970s that schizophrenia might be twice as prevalent in the United States as in Great Britain (Cooper et al. 1972, Pope \& Lipinski 1978). Such differences in rates of diagnosis represented more than an academic problem. With the discovery of lithium therapy, which is efficacious for bipolar disorder but not for schizophrenia (Leucht et al. 2003), it became critical to get these diagnoses right. Did these transatlantic differences reflect true differences in prevalence or did they result from divergent approaches to diagnosis?

After the DSM-III (Am. Psychiatr. Assoc. 1980) defined schizophrenia as a chronic illness (based on the six-month criterion mentioned above), the differences in prevalence between Great Britain and the United States melted away. The differences had resulted from the fact that unlike British practitioners, American practitioners had made diagnoses of both acute and chronic forms of schizophrenia. As a result of DSM-III, acute schizophrenia disappeared as a diagnosis. There was, in addition, potential therapeutic benefit to a subset of patients who were rediagnosed from acute schizophrenia to bipolar disorder (Pope \& Lipinski 1978) with the implication that they might receive a therapeutic trial of lithium.

Despite marked improvements over DSM-I and DSM-II, neither the DSM-III (Am. Psychiatr. Assoc. 1980) nor any phenomenologically based diagnostic system can fully solve the reliability problem. In clinical encounters, information must be elicited from patients who may lack insight into their symptoms as a result of their illness or who may have complex motives ranging from shame to paranoid ideation to drug-seeking that influence reporting of symptoms. Moreover, it can prove quite difficult to interpret the diagnostic significance of some symptoms, e.g., whether a particular highly overvalued idea represents an obsession or a psychotic delusion. Ultimately, a laboratorybased system will be required in order to make additional substantial improvements in reliability.

\section{CLASSIFICATION}

Classifications are cognitive structures imposed on data to achieve particular goals. Given the complexity of human psychology, biology, and illness, any classification in these realms is likely to be plagued by stubborn bits of data that refuse to fit neatly into uniform, well-ordered classes (see sidebar The Challenges of Classification in Living Systems). There is a reasonable consensus that the goals of a classification of mental disorders should be optimized for clinical utility (and the DSM-IV and ICD-10 purport to do this) without ultimately sacrificing validity. Goals such as clinical utility and validity do not specify unique taxonomies, however. For 
example, in the DSM-IV, autism is justifiably classified as a developmental disorder (C. Walsh et al. 2008), but a different system could have reasonably classified autism primarily in terms of deficits in social cognition (Baron-Cohen \& Belmonte 2005, Losh et al. 2009).

In disease classification, the gold standard is either etiology or etiology modified by pathophysiology (e.g., a single genetic mutation or infectious agent may give rise to divergent disease processes in some cases). For mental disorders, etiologic and pathophysiologic information is still sparse and thus cannot yet yield valid disease definitions. The result is a classification based, of necessity, on phenomenology. Given the extraordinary challenges that lie ahead to gain understanding of the etiologies and pathologic processes underlying mental disorders, phenomenology must, in the main, continue to play the dominant role in DSM-V and ICD-11. The need to depend on phenomenology, and therefore only surface characteristics, will likely contribute to continued errors (only to be discovered later) in the lumping and splitting of symptom clusters into disorders. The current classification of mental disorders can be analogized to the taxonomy of life (see sidebar The Challenges of Classification in Living Systems) prior to the ability to observe evolutionary relationships and more recently to sequence DNA: Convergent evolution has given rise to similar traits many times, and without deeper understandings, some of these will inevitably be confounded.

Although there was no reasonable alternative to phenomenologically based diagnoses in formulating the DSM-III (Am. Psychiatr. Assoc. 1980), a series of contingent top-down decisions were made that have, in my view, led to problems. The need to rely on clinical observation instead of etiology or pathophysiology did not entail the substantial (and arguably scientifically premature) splitting of the universe of psychopathology into many highly specified disorders, nor did it require that essentially all of psychopathology be parsed into discontinuous categories (as opposed to some use of quantitative or dimensional descriptions).

\section{THE CHALLENGES OF CLASSIFICATION IN LIVING SYSTEMS}

The challenges of classification in the life sciences are well illustrated by the most fundamental classification project in biology, the taxonomy of species, which in its current form dates from Linnaeus (1707-1778). Since Darwin, the organizing principle of the resulting tree of life has been the evolutionary relationships among taxa rather than similarity of traits (phenotypes). Thus, insects, birds, and bats are not immediate relatives even though they have all separately evolved wings. The relationships among species are not entirely a settled matter, however. Indeed, there have been many recent adjustments to the tree of life as burgeoning genomic information has supplemented phenotypic observations (Dunn et al. 2008). Even as more complete genetic data are generated, difficult problems will remain. The classical definition of a species is an interbreeding population of organisms (a concept that assumes sexual reproduction). However, microorganisms are haploid and generally reproduce asexually. Thus, the concept of species that applies to plants and animals sits uneasily with microorganisms. What is more, microorganisms may exchange DNA segments in processes unrelated to reproduction; thus, evolutionary relationships cannot be defined with the same clarity as for plants or animals.

Although I argue that there are significant shortcomings to the definitions that the DSMIII (Am. Psychiatr. Assoc. 1980) imposed on mental disorders, it is also important to recognize that major disorders contained therein, such as schizophrenia, bipolar disorder, autism, major depression, and obsessive-compulsive disorder, pick out highly replicable features of psychopathology. The evidence includes the stability of symptom clusters and clinical course across historical time (Burton 1621) and across cultures. For example, significant syndromal similarities have been described across countries and cultures for autism (Wakabayashi et al. 2007), schizophrenia (Jablensky et al. 1992), bipolar disorder (Fekadu et al. 2006), obsessivecompulsive disorder (Matsunaga et al. 2008), and other major disorders. In addition, many of the major disorders exhibit a high degree of familial aggregation (Kendler et al. 1997). Recognizable symptom clusters cohere within and

\section{Disease}

classification: a

listing of diseases clustered by relatedness, e.g., cancers, metabolic diseases, infectious diseases, unintentional injuries. The

International Classification of Diseases was initially developed to facilitate statistical reporting of causes of mortality across countries. For disease classification, the gold standard is etiology and pathophysiology 
Table 1 Relative risk of selected disorders compared with general population risk

\begin{tabular}{l|c|c|c}
\hline Disorder & $\begin{array}{c}\text { Population } \\
\text { prevalence }\end{array}$ & $\boldsymbol{\lambda}_{\mathbf{1}}$ & Heritability \\
\hline Autism (narrow) & $0.2 \%$ & 25 & 0.9 \\
\hline Autism (broad) & $0.7 \%$ & 25 & 0.9 \\
\hline Schizophrenia & $1.0 \%$ & 9 & $0.8-0.9$ \\
\hline Bipolar disorder & $1.0 \%$ & 8 & $0.7-0.8$ \\
\hline Major depression & $17 \%$ & $2-5$ & 0.35 \\
\hline
\end{tabular}

$\lambda_{1}$ denotes fold elevation in risk of the disorder over population base rates for a first-degree relative of an affected proband. Thus, for example, the sibling of a person with schizophrenia has a nine-fold increased risk over the population prevalence of $1 \%$, i.e., a 9\% risk of schizophrenia. Reprinted from Hyman 2008.

across generations, although not nearly with the precision predicted by DSM-III and DSMIV diagnostic categories. Twin studies (Kendler 2001) and, where performed, adoption studies (Kety et al. 1971, Sigvardsson et al. 1996), suggest that much of familial aggregation is explained by heredity. Indeed, autism, schizophrenia, and bipolar disorder number among the most heritable of common, genetically complex illnesses (Table 1; Merikangas $\&$ Risch 2003). If the major disorders were arbitrary chimeras created by the original DSM-III task force, the high levels of historical and cross-cultural similarity, familial aggregation, and heritability would be difficult to explain.

Even when genetic and nongenetic risk factors for mental disorders are eventually identified, it will remain a challenge to draw disease boundaries. This challenge derives from the remarkable etiological complexity of common mental disorders despite their substantial heritability (see sidebar Genetically Complex Disorders). Modern molecular genetic studies (currently most advanced for autism, schizophrenia, and bipolar disorder) indicate that no single genetic variant will prove either necessary or sufficient for any of these diagnoses (Happe et al. 2006, Int. Schizophr. Consort. 2009) and that a very large number of genes in different combinations contribute to aggregate population risk of these and other mental disorders. Indeed, there is strong evidence for both shared and unshared genetic risk factors among mood and anxiety disorders (Kendler et al. 1992) and among autism, schizophrenia, bipolar disorder, and a variety of other psychotic disorders (Cardno et al. 2002; Craddock et al. 2005, 2006; Green et al. 2005; Int. Schizophr. Consort. 2009; Kilipinen et al. 2008; Lichtenstein et al. 2009). Given this complexity and heterogeneity, which will be complicated further when developmental and environmental risk factors are identified with certainty, I use the term "diagnostic validity" throughout this review, not to suggest that there is some Platonic ideal of autism or schizophrenia or any other disorder, but rather as shorthand to signify definitions that capture families of closely related disorders with similar pathophysiology.

\section{THE INTELLECTUAL BASIS OF DSM-III}

Robins \& Guze (1970) enunciated the proximate intellectual underpinnings of the DSM-III (Am. Psychiatr. Assoc. 1980); in turn, they relied on the foundational work of Emile Kraepelin (1899), who attempted to ground the diagnoses of schizophrenia (dementia praecox in his terminology) and bipolar disorder (manic-depressive illness) on close observation, especially taking the course of illness into account. Using schizophrenia as their example, Robins \& Guze (1970) argued that reliable and valid diagnoses would follow from observations in five domains: (a) clinical description, (b) laboratory studies, $(c)$ delineation of one disorder 
from another, $(d)$ follow-up studies (i.e., observing diagnostic stability over time), and (e) family studies. They believed that as knowledge accumulated, observations from these five areas would converge on valid disorder definitions. In their view, the Kraepelinian emphasis on long-term follow-up was an important indicator that a symptom cluster, observed at one time in a patient's life, represented a valid disorder as opposed to an accidental conjunction of symptoms occurring at a single point in time. Family studies might demonstrate that particular symptom clusters were transmitted from one generation to the next, again providing evidence that a diagnosis represented a natural kind (with shared etiological factors) rather than a chance co-occurrence of symptoms in a single individual. Their work motivated the development of two sets of diagnostic criteria intended for the identification of homogeneous populations for research, the Feighner criteria (Feighner et al. 1972) and the research diagnostic criteria (Spitzer et al. 1975). These, in turn, became important models for the DSM-III (Am. Psychiatr. Assoc. 1980). Indeed, Spitzer, who led the development of the DSM-III (Am. Psychiatr. Assoc. 1980), was lead author of the research diagnostic criteria (Spitzer et al. 1975).

\section{THE LIMITATIONS OF CATEGORICAL DIAGNOSES}

A significant assumption made by Robins \& Guze (1970) was that mental disorders would best be conceptualized as discrete categories, discontinuous from each other and from health. Indeed, the third validator in their list of five was delineation of one disorder from another, perhaps in reaction to psychoanalytic approaches that saw all psychopathology on a developmental continuum. A uniformly categorical approach was subsequently adopted by the Feighner and research diagnostic criteria (Feighner et al. 1972, Spitzer et al. 1975) and, with one exception (mental retardation), wholly embraced by the DSM-III (Am. Psychiatr. Assoc. 1980).

\section{GENETICALLY COMPLEX DISORDERS}

Despite the significant role for genes in risk of common mental disorders (Table 1), progress has been frustratingly slow in identifying the precise genetic variants responsible. This difficulty results, in part, from the lack of objective tests to define phenotypes for genetic analysis. Perhaps the greater problem is genetic complexity, which signifies that there are diverse genetic pathways involving large numbers of genes that contribute to risk of any given disorder. Genetic complexity of mental disorders was first predicted from family studies because the patterns of inheritance across generations did not exhibit what would be predicted for disorders caused deterministically by single genes, i.e., Mendelian dominant, recessive, or sex-linked patterns of inheritance. Similarly, studies comparing monozygotic twin pairs (alike in $100 \%$ of their DNA) and dizygotic twin pairs (sharing on average $50 \%$ of their DNA) also did not yield the predicted Mendelian ratios.

At the extremes, diverse genetic pathways to similar disease traits have been shown to result from $(a)$ interactions among multiple genetic variants that are common in human populations, often described as the common disease-common variant hypothesis, or from $(b)$ diverse rare, highly penetrant mutations, with each individual mutation causing disease in a small number of families. An example that illustrates the common disease-common variant hypothesis is maturity-onset (type 2) diabetes mellitus (Zeggini et al. 2008). An example that illustrates the phenotypic convergence of independent mutations in different families is retinitis pigmentosa (Daiger et al. 2007, Pacione et al. 2003). In type 2 diabetes, the variants that contribute to risk are generally single base changes in DNA, i.e., single-nucleotide polymorphisms (SNPs) that are not individually deleterious, but produce risk through interaction with each other and with nongenetic factors. Retinitis pigmentosa is caused by a large number of different deleterious mutations in different genes, each of which can act alone to cause pigmentary degeneration of the retina and thus blindness. In other words, each deleterious mutation acts as a single gene "Mendelian" disorder within a family, but in aggregate, different families are affected by a large number of distinct mutations in different genes. Depending on the precise mutation inherited, retinitis pigmentosa trait can be a dominant or recessive trait, and the precise timing and severity of symptoms will differ.

SNPs can produce deleterious mutations, especially when they influence protein structure or mRNA splicing. Copy number variations (CNVs), which represent larger structural alterations including deletions, insertions, duplications, or more complex 
genomic rearrangements, are more likely than SNPs to produce biological effects by disrupting one or more genes or quantitatively altering gene expression. In addition to harboring millions of SNPs, the human genome harbors substantial CNVs, some inherited across generations and some occurring de novo. The evidence to date concerning the genetics of autism and schizophrenia suggests a middle ground between the models described for type 2 diabetes and retinitis pigmentosa. Both common variants and rare, highly penetrant mutations appear to play a role in both disorders, with marked differences across individuals (Int. Schizophr. Consort. 2008, 2009; Morrow et al. 2008; O'Donovan et al. 2008; Shi et al. 2009; T. Walsh et al. 2008; Weiss et al. 2008; $\mathrm{Xu}$ et al. 2008). There is less information to date about other mental disorders, but progress is being made, most notably in bipolar disorder (Ferreira et al. 2008, Int. Schizophr. Consort. 2009).

\section{Categorical}

diagnosis: a disease, disorder, or risk state that can be qualitatively separated from being well and also from other diseases or disorders, e.g., tuberculosis or chronic myelogenous leukemia
An alternative approach, common in general medicine, is to represent some disorders as quantitative (or dimensional) rather than qualitative deviations from health. Examples of disorders that are most usefully represented as categories are pneumococcal pneumonia and small cell carcinoma of the lung. Disorders (including risk states) better represented as quantitative deviations from health include type 2 diabetes mellitus, hypertension (which is measured along two dimensions, systolic and diastolic blood pressure), and dyslipidemias (which are measured along multiple dimensions, including different fractions of serum cholesterol and triglycerides). A categorical classification logically posits discontinuities or "zones of rarity" in symptom distributions that provide natural boundaries between disorders and between disorder and health (Kendell \& Jablensky 2003). In contrast, when disorders are represented quantitatively, they are understood to be continuous with normalcy, lacking sharp discontinuities that would support a qualitative separation.

Because dimensional disorders are continuous with normalcy, diagnostic thresholds must be set, ideally grounded in empirical outcomes data. For hypertension and hypercholesterolemia, multiple thresholds have been set based on current follow-up data that create modifiable de facto categories or "bins" that call for different levels of clinical response ranging from vigilant follow-up to behavioral measures to increasingly potent medical interventions. Although guided by data, the selection of thresholds for diagnosis and treatment is a matter of policy. For example, longitudinal studies have documented levels of increasing risk of cardiovascular events that correspond to increasing levels of low-density lipoprotein (LDL) cholesterol, systolic blood pressure, or diastolic blood pressure. Such information is then used to set (and recently to revise) thresholds for diagnosis and intervention (Chobanian et al. 2003, Grundy et al. 2004). Interestingly, recent revisions to thresholds for intervention in hypercholesterolemia were influenced by the safety and efficacy of LDL-cholesterol-lowering statin drugs. Although the diagnosis of mental disorders lacks the intrinsically quantitative laboratory measures used for diabetes, hypertension, or lipid disorders, variations in behavior, severity of symptoms, and levels of impairment have long been represented successfully on quantitative scales.

For mental disorders that can appropriately be represented by quantitative dimensions, scores on the relevant symptoms scales could be correlated with outcomes, such as progression to greater symptom severity, development of additional symptoms, or worsening measures of functional impairment. The results of such research would better justify thresholds for diagnosis and treatment than currently exist. For the present, clinicians are forced to make an intuitive judgment call, often based on a "clinical significance" criterion that is included with the symptom lists of many disorders. To meet criteria for Major Depression, for example, it is required not only that the person meet the required symptom count, but also that: "The symptoms cause clinically significant distress or impairment in social, occupational, or other important areas of functioning" (Am. Psychiatr. Assoc. 1994). This approach fails both because it denies an appropriate clinical status to early or milder symptom presentations (Keller 
et al. 1983, Shankman et al. 2009), thus impeding preventive interventions, and because it does not answer the criticism of excessive medicalization of life problems (Healy 2006). Indeed, the current positioning of the clinical significance criterion in many disorder definitions of the DSM-IV illogically confounds a severity measure with a symptom list (Sartorius 2009). Empirically grounded, graded diagnostic thresholds, as exist for hypertension, would seem to require a separation of symptoms and signs from severity measures even for categorical disorders.

Perhaps the major problem with the categorical approach is that for many disorders in the DSM-IV, there is no evidence for discontinuities in symptom profiles (zones of rarity) and often evidence for the opposite. Disorders in which evidence favors a dimensional approach include major depression (Kendler \& Gardner 1998), obsessive-compulsive disorder (MataixCols et al. 2005), autism (Di Martino et al. 2009, Hoekstra et al. 2007), attention deficit hyperactivity disorder (ADHD; Hudziak et al. 2005), and personality disorders (Skodol et al. 2002a,b). For all these diagnoses, symptoms listed in their criterion sets are also normally distributed in the general population. The dimensional nature of personality disorders has long been argued (Skodol et al. 2002a,b; Widiger \& Mullins-Sweatt 2009). Parenthetically, beginning with the DSM-III (Am. Psychiatr. Assoc. 1980), personality disorders have also been subject to what can only be described as an arbitrary and scientifically strange decision to be separated from other disorders on a separate diagnostic axis, Axis II. Subsequent research has found no convincing scientific justification for this separation (New et al. 2008; Siever \& Davis 1991; Skodol et al. 2002a,b).

The only clearly dimensional representation of disorder in the DSM-IV is mental retardation (also listed on Axis II even though autism, a common cause of mental retardation, is an Axis I disorder). This dimensional representation is entirely appropriate given the continuous distribution of IQ in the population. Indeed, it has been argued that mental retardation could provide a model for the adoption of dimensional definitions in the DSM-V (Widiger \& Trull 2007) as well as a model for the use of a standardized psychological test as a laboratory measure in diagnosis (Widiger \& Clark 2000). Mental retardation is complex, with diverse causes ranging from specific mutations such as trisomy 21 to specific gene-environment interactions as occur in untreated phenylketonuria to presumed interactions of many common genetic variants with developmental and environmental factors. Despite known specific causes and many more still unknown, IQ remains a clinically useful and predictive clinical dimension in that an IQ of 70 or below has been convincingly correlated with significant impairment.

Research from animal models, cognitive neuroscience, brain imaging, and pharmacology have produced strong arguments that addictive disorders (Hyman et al. 2006) and some anxiety disorders (Yehuda \& LeDoux 2007) represent excessive activation of normal neural mechanisms within reward and fear circuits, respectively. For example, several anxiety disorders, most clearly posttraumatic stress disorder, may result from a quantitative imbalance between normal processes of fear conditioning and of extinction or reappraisal (Rauch et al. 2006, Yehuda \& LeDoux 2007). On this model, failure of some individuals to recover fully from broadly expectable effects of trauma suggests a biological mechanism that is continuous with normalcy. In $\mathrm{ADHD}$, a recent longitudinal structural neuroimaging study that examined changes in cortical thickness with age concluded that symptoms result from maturational delay, especially of prefrontal cortex, but not from a qualitatively abnormal pattern of cortical development (Shaw et al. 2007).

Employment of categorical approaches to disorders that are better represented as quantitative deviations from health is not simply an arcane matter of taxonomy, but also creates significant problems for clinical practice and research. In development of clinical practice guidelines, the fiction of a qualitative separation from normalcy creates obstacles to 
setting and later revising data-driven thresholds for diagnosis and intervention of dimensional disorders. Lacking information that links outcomes quantitatively to symptoms, it is difficult for clinicians to justify early interventions that might prevent severe psychopathology or interventions for milder but impairing symptoms (Keller et al. 1983, Shankman et al. 2009). Clinicians are forced to make "subthreshold" or atypical diagnoses (Jackson et al. 2007), which are not likely to be insured, or to engage in diagnostic "bracket creep" in order to gain reimbursement for treatment.

The conceptualization of ADHD as a category discontinuous from normalcy is not only implausible, but also inhibits the kind of research that would improve the clinical utility of the diagnosis and perhaps its validity. DSMIV calls for the diagnosis of ADHD when six or more symptoms of inattention (specified in a list) and six or more symptoms of hyperactivity and impulsivity (from other lists) have persisted for at least six months "to a degree that is maladaptive and inconsistent with developmental level" (Am. Psychiatr. Assoc. 1994). These arbitrary symptom counts do not provide effective tools for family doctors and other primary care practitioners, who evaluate the majority of children for $\mathrm{ADHD}$, to make a diagnosis against the moving developmental target of brain maturation (Angold et al. 2000). If ADHD were instead portrayed as quantitative deviations from the mean on scales of attention, hyperactivity, and impulsiveness, benchmarked for age, then thresholds for diagnosis and treatment could be set in analogy to how pediatricians measure children against standardized growth curves. From a policy point of view, individuals concerned with overdiagnosis or underdiagnosis could, for the most part, be engaged in debates on where to set thresholds for treatment rather than in current debates as to whether ADHD exists at all as a category distinct from health.

The development, where appropriate, of quantitative scales that are both scientifically justified and clinically useful for the diagnosis and treatment of mental disorders will be a challenging process, proceeding over years.
Undoubtedly, this process will begin with clinically ascertainable scales, but will eventually involve cognitive measures and, in the more distant future, perhaps structural or functional brain imaging and other technologically based measures. Given that the revisions of the DSM-IV and the ICD-10 are well under way, the process of developing and testing quantitative measures will, in most cases, have to lag the initial publications of DSM-V and ICD-11. Fortunately, both the American Psychiatric Association (Regier et al. 2009) and World Health Organization have committed to making DSM-V and ICD-11 living documents. This policy has the benefit that quantitative scales will not have to be developed for artificial publication deadlines, but can be added later without having to wait a decade or more for DSM-VI and ICD-12.

\section{THE PROBLEM OF OVERSPECIFICATION}

Basing diagnoses of heterogeneous forms of psychopathology on rigid, highly specified lists of operationalized criteria trades interrater reliability for the exclusion of a significant number of individuals who by other measures would be counted as affected. Problems created by rigid overspecification are exemplified by comparing diagnoses made with DSM-IV (Am. Psychiatr. Assoc. 1994) and ICD-10 (World Health Org. 1992) for disorders in which the intention was to identify the same patients. Although there are some principled disagreements between the DSM-IV and the ICD-10, many of the differences in operationalized criteria are the accidental results of having two parallel processes of criterion writing. Slade \& Andrews (2001) used a single structured interview, the Composite International Diagnostic Interview, administered to a community sample of 10,641 people, to derive DSM-IV and ICD-10 diagnoses. They found that small differences in wording resulted in the identification of different individuals as being affected. In a smaller sample enriched for prevalence of mental disorders, Andrews et al. (1999) found a concordance between DSM-IV 
and ICD-10 criteria of $83 \%$ for a depressive episode, only $64 \%$ for obsessive-compulsive disorder, and only $35 \%$ for posttraumatic stress disorder. Thus, the operationalized criteria of DSM-IV and ICD-10 criteria are so rigid as to exclude large numbers of plausibly affected individuals (indeed identified by the cognate system) who are likely in need of treatment.

Among users of the DSM-IV, the rigidity and narrowness of diagnostic criteria result in the widespread use of Not Otherwise Specified (NOS) diagnoses. The result is an odd paradox: Some patients are placed into a narrowly defined box, and others, who do not precisely match the DSM-IV criteria, are placed in a largely unspecified residual category. The relative percentage of NOS diagnoses used in clinical settings varies according to disorder clusters and the care with which different clinical communities attend to DSM-IV criteria. It appears, however, that NOS diagnoses may approach a majority in the autism spectrum (de Bruin et al. 2007), eating disorders (Fairburn \& Bohn 2005), and personality disorders (Verheul et al. 2007). Overall, a significant fraction of patients who present in primary care settings do not fit the highly specified criteria of the disorders named within the DSM-IV and receive an NOS diagnosis with unpredictable implications for treatment intervention (Jackson et al. 2007).

Objective tests (unless they involve a difficult and operator-dependent laboratory procedure) are intrinsically more reliable than clinical observation. It is also the case that objective medical tests, such as measurements of systolic and diastolic blood pressure or glucose tolerance, are less likely to overspecify features of a disorder than the operationalized criteria of DSM-IV. The most useful objective tests are selected to capture a meaningful group that can then be subdivided by additional tests and clinical observation. In contrast, a classification that prioritizes interrater reliability but is based on phenomenology takes on the risks that are well exemplified by the DSM-IV: a highly specified, but in the end, arbitrary list of inclusion and exclusion criteria. When combined with the categorical approach of the DSM-IV, with its rigid and equally arbitrary thresholds, it is not surprising that many patients fall into NOS categories or must be described as "atypical."

\section{THE PROBLEM OF COMORBIDITY}

Comorbidity is so extensive among DSM-IV diagnoses (Kessler et al. 2005b) as to forcefully raise questions about the underlying structure and assumptions of the classification (Kendell \& Jablensky 2003). Of course among general medical disorders and mental disorders alike, individuals may have multiple illnesses with independent etiologies or may have one condition that is an independent risk factor for another. Thus, for example, smoking and diabetes are independent risk factors for atherosclerosis, and mania is a risk factor for substance use disorders (Regier et al. 1990). Much of the unease about comorbidity among mental disorders results from the fact that rates are very high (often the majority of patients in clinical settings) within "families" or clusters of related illnesses. Thus, for example, comorbidity is characteristic of individuals with diagnoses of mood and anxiety disorders (Clark et al. 1995; Kessler et al. 2005a,b; Mineka et al. 1998; Moffitt et al. 2007) and personality disorders (McGlashan et al. 2000, Skodol 2002a). It is also common within certain groups of childhood disorders, including ADHD (Galanter \& Leibenluft 2008, Goldstein \& Schwebach 2004), obsessive-compulsive "spectrum" disorders (Pallanti \& Hollander 2008), and psychotic disorders (Fraguas et al. 2007). The open question raised by these observations is whether individuals with comorbidity within a family of disorders are better understood as having two or more distinct DSM-IV (Am. Psychiatr. Assoc. 1994) disorders or as having a single disorder in which complex etiological factors give rise to diverse symptom complexes that may change with time and environmental exposures (Cardno et al. 2002, Kendler et al. 1992, Krueger \& Markon 2006). If a substantial fraction of comorbidity is an artifact of excessive 
splitting of pathophysiologically closely related conditions, then the situation is clearly exacerbated by the hard boundaries stipulated by operationalized criteria between putatively categorical disorders.

Historically, there was an attempt to suppress the high levels of comorbidity potentially created by the DSM-III (Am. Psychiatr. Assoc. 1980) by including an "exclusion criterion" in many DSM-III disorder definitions. The exclusion criterion stipulated that a disorder could not be diagnosed if it was "due to another disorder." This criterion depressed rates of comorbidity by forcing a single primary diagnosis in many situations. The analogy might be to diabetes mellitus where subsequent kidney disease (diabetic nephropathy) might be subordinated to the underlying disorder even if recognized as a clinical entity requiring independent treatment. Among mental disorders, this hierarchical approach was found to be essentially impossible to operationalize (Robins 1994). For example, it was often unclear in a given patient which disorder (e.g., depression or an anxiety disorder) should be considered primary and which secondary. The exclusion criterion was thus removed from the Diagnostic and Statistical Manual of Mental Disorders, third edition, revised (DSM-III-R; Am. Psychiatr. Assoc. 1987), with the result that the high prevalence of comorbidity was unmasked (Kessler et al. 1996).

The observation that comorbidity may be more common than pure "types" within some domains of psychopathology (Moffitt et al. 2007) suggests a state of affairs in which artificial diagnostic silos were created by the combination of exuberant splitting and the highly specified, operationalized criteria of DSM-III (Am. Psychiatr. Assoc. 1980). During the development of DSM-III, the process of splitting larger clusters into more specific disorders elicited substantial debate and disagreement (Lane 2007), but these disagreements have largely disappeared, not because of scientific progress, but rather, I would argue, because named disorders became passively accepted and reified.
Comorbidity is not simply a matter of concern for health statistics and epidemiology. Given the status of the DSM-IV in the scientific and regulatory firmament, all clinical trials for drug registration and most clinical trials overall are conducted among patients diagnosed with a single, "pure" DSM-IV disorder. In some areas of psychopathology, these individuals may actually represent an atypical minority of those in need of treatment (Moffitt et al. 2007). Recent large clinical trials that enrolled more realistic populations, such as the Sequenced Treatment Alternatives to Relieve Depression (STAR*D), have found that treatments efficacious for pure DSM-IV disorders, such as Major Depression, are less so in the large fraction of patients who have additional symptoms such as anxiety (Howland et al. 2009, Rush et al. 2006).

In order to serve the long-term needs of research, including treatment development, and of clinical care, the DSM-V should be structured to facilitate a bottom-up reanalysis of the historically premature and possibly excessive splitting within domains of pathophysiology stipulated by the DSM-IV (Am. Psychiatr. Assoc. 1994). As I have argued previously (Hyman 2007) and as I argue below, this goal can be facilitated without significant disruption of current practice, at least in the short term. Without requiring change to the criteria for current disorders, the diagnostic entities could be regrouped into new large clusters or families based on the best current etiological or neurobiological hypotheses. Thus, for example, groups could include fear-based anxiety disorders (thought to reflect the interaction of amygdalabased fear circuitry with prefrontal cortex), an obsessive-compulsive disorder spectrum (thought to involve frontal-striatal circuitry), addictive and related impulse-control disorders (that involve brain reward circuits), and psychotic disorders, including what is now classified as schizotypal personality disorder. Regrouping of this kind, literally a change in the organization of the table of contents, can help move the relevant science forward 
if funding agencies and journals welcome research that examines the implications of new (or fewer) boundaries within these larger clusters and tests dimensional approaches that cut across current diagnostic silos. For example, one could hold in abeyance the notion that there are natural kinds, qualitatively different from each other, called panic disorder, simple phobias, social phobia, and posttraumatic stress disorder, and begin again with a cluster based on dysregulated fear circuitry (Andrews et al. 2009, Delgado et al. 2008, Rauch et al. 2006). Then from the bottom up, investigators could determine whether the cognitive and affective abnormalities, neurobiology, genetics, symptoms, course, and treatment responses were more effectively and parsimoniously conceptualized using boundaries different from DSM-IV or dimensionally rather than categorically (Hyman 2007). The results of such research might be incorporated into later revisions of the DSM-V and ICD-11, or if very extensive, could pave the way for DSM-VI and ICD-12.

\section{FAMILY AND GENETIC DATA DO NOT CONFIRM DSM-IV DISORDER BOUNDARIES}

Far from providing the predicted validation of schizophrenia or any other mental disorder as categories delineated from all others, family and genetic studies have dramatically undercut the Robins \& Guze (1970) approach to classifying psychopathology. When Robins and Guze developed their conception of major disorders as "pure types" defined by symptom clusters, laboratory tests, delineation of one disorder from another, long-term follow-up, and family studies, they could not have imagined the high degree of genetic complexity that would be found to characterize mental disorders (see sidebar Genetically Complex Disorders). An already large and steadily accumulating body of data suggests that as for other common diseases (Hunter et al. 2008), the population risk of autism, schizophrenia, bipolar disorder, and other mental disorders results from the interaction of a large number of different combinations of genetic and nongenetic risk factors (Craddock et al. 2006, Freitag 2007, Happe et al. 2006, Int. Schizophr. Consort. 2009). Within human populations, no single gene variant or genomic locus appears to be necessary or sufficient to produce any of the major, common mental disorders. Evidence that is emerging at an accelerating pace also suggests that in different individuals, autism and schizophrenia may result either from the interaction of a large number of common genetic variants (Ferreira et al. 2008, Int. Schizophr. Consort. 2009, O'Donovan et al. 2008) or from rare, highly penetrant mutations (Int. Schizophr. Consort. 2008, Morrow et al. 2008, T. Walsh et al. 2008, Weiss et al. 2008, Xu et al. 2008), perhaps acting against a risk-laden genetic background produced by common variants (Bodmer \& Bonilla 2008). Highly penetrant mutations may result from single-nucleotide polymorphisms (SNPs) or more likely from copy number variation (CNV). CNV may be inherited (Millar et al. 2000) or may occur de novo in the affected individual, leading to new onset of disorder within a family that can be passed to subsequent generations ( $\mathrm{T}$. Walsh et al. 2008).

In addition to the remarkable etiological heterogeneity of individual symptom complexes, there is strong evidence that some DSM-IV disorders (Am. Psychiatr. Assoc. 1994) share a subset of their genetic risk factors with other DSM-IV disorders. On the basis of twin studies, Kendler et al. (1992) have adduced evidence of partly shared genetic risk factors for major depression and generalized anxiety disorder, which might explain the high rates of comorbidity under the current diagnostic regime (Kessler et al. 2005a,b; Moffitt et al. 2007). On the basis of molecular genetic studies, schizophrenia and bipolar disorder appear to have both shared and unshared genetic risk factors (Int. Schizophr. Consort. 2009). Indeed, family and molecular genetic studies of 
autism, schizophrenia, and bipolar disorder illustrate the challenges for disorder definition and classification given the genetic complexity, independent segregation of risk genes across generations, and sharing of some risk genes among different symptom clusters (and among different DSM-IV disorders).

Many modern studies of families with schizophrenia and bipolar disorder reveal that significant symptom clusters fail to cohere across generations, giving rise to diverse phenotypic variations, not all of which neatly fit DSM-IV criteria (Craddock et al. 2005, 2006). Indeed, single families may contain individuals diagnosed with schizophrenia, bipolar disorder, and intermediate conditions such as DSM-IV schizoaffective disorder (Berrettini 2000, Cardno et al. 2002, Laursen et al. 2005, Lichtenstein et al. 2009). Such scenarios likely reflect the precise mixture of risk genes passed to each child as well as developmental events involved in wiring the brain and diverse environmental factors.

As noted, specific SNPs or CNVs are not necessarily correlated with a single DSM-IV diagnosis, an observation that suggests serious drawbacks for gene-based diagnostic testing in the near term. One dramatic example comes from a Scottish family in which a balanced translocation of a segment on chromosome 1 was found to be associated, initially, with schizophrenia. This segment contained two genes that were named Disrupted in Schizophrenia 1 and 2 (DISC1 and DISC2; Millar et al. 2000, St. Clair et al. 1990). Even within the index family, however, the translocation was found, not only in individuals with schizophrenia, but also in subjects with schizoaffective disorder and recurrent major depression (St. Clair et al. 1990). DISC1 has emerged as a biologically compelling candidate gene for risk of neuropsychiatric disorders that has engendered additional study (Mao et al. 2009). Thus, in addition to the translocation found in the initial Scottish family, the DISC1 gene has been found to harbor multiple SNPs in other families. To date, variations in the
DISC1 sequence have been associated not only with schizophrenia, schizoaffective disorder, bipolar disorder, and major depression, but also with both broad and narrow phenotypes of autism (Kilipinen et al. 2008).

These findings do not mean that cases of DSM-IV schizophrenia or bipolar disorder never breed true, or that Kraepelin's distinction between dementia praecox (schizophrenia) and manic depressive illness (bipolar disorder) is totally without merit (Kraepelin 1899). Instead, the findings signify that schizophrenia and bipolar disorder are etiologically and clinically heterogeneous syndromes rather than tightly defined categories as portrayed in the DSMIV (Fischer \& Carpenter 2009). Moreover, given the large number of genes that contribute to schizophrenia and bipolar disorder, mixing of parental risk genes in offspring would be expected to give rise to diverse intermediate forms of illness that would likely include schizoaffective disorder and other syndromes characterized by psychosis (Fanous et al. 2001, Laursen et al. 2005, Lichtenstein et al. 2009, Malhi et al. 2008). From the time that DSM-III (Am. Psychiatr. Assoc. 1980) was published, schizoaffective disorder has stood out as stubbornly resistant to validation (Pope et al. 1980). Given the etiological hypotheses just described, it is not surprising that there are many patients with both schizophrenia-like symptoms and symptoms of a major mood disorder. They are not well captured, in their diversity, by a categorical system defined by operationalized criteria. Given the etiological complexity just described, it is not surprising that the Robins \& Guze (1970) validators have not converged onto natural kinds. The wholesale adoption by the DSM-III (Am. Psychiatr. Assoc. 1980) of phenomenologically based operationalized criteria in the service of interrater reliability, and of a wholly categorical approach to disorder, unwittingly exacerbated the difficulty of capturing etiologically diverse and phenotypically heterogeneous syndromes. 


\section{WHAT IS TO BE DONE?}

At the beginning of this review, I noted that scientific understandings of the etiologies and pathologic processes underlying mental illnesses were still in early stages. Significant progress has been made in molecular genetic analyses of risk for autism, schizophrenia, and to a slightly lesser extent, bipolar disorder. There is, however, a long way to go with respect to these conditions, and progress has been slower on the genetics of other forms of psychopathology. There has also been real progress in neurobiology, but it has not yet reached a stage where it can contribute usefully to individual disease definitions. Given that significant changes to existing diagnostic criteria will be disruptive to research, clinical practice, and to administrative applications of the DSM classification, it is important to ask whether the benefits of making changes outweigh possible negative effects at this stage of scientific knowledge. I argue that the risk of doing nothing will, at a minimum, impede the disease-related research that is required to achieve a more valid classification in the coming years. The substantial need for NOS criteria, excessive comorbidity, the mismatch between real-world populations and "pure" clinical trials samples, arbitrary and rigid diagnostic thresholds, and the gulf between DSM-IV disorders and emerging results of genetic studies all point to significant failures inherent in the current DSM-IV classification. The problems that have emerged within the DSM "paradigm" (based on operationalized criteria that define a large number of categorical disorders) cannot be fixed by tinkering with existing criteria sets or by adding or subtracting diagnoses at the margins. Given the early state of the science, however, the kind of changes that I would prescribe for the DSM-V are not replacing old flawed guesses with new guesses about disorder definitions. I believe that the most useful modifications will be those that invite scientists to move beyond currently reified diagnoses in order to provide the information that will lead, ultimately, to a valid classification. It is a good sign that the NIMH has begun a program to develop new ways of classifying mental disorders for research purposes, called the Research Domain Criteria (RDoC) initiative, meant to incorporate data from genetics, psychology, human and animal neurobiology, and clinical trials. The DSM-V should ideally be structured in a way that facilitates rather than impedes such efforts.

In order to facilitate progress while minimizing disruption, I argue that changes to existing criterion sets should only occur when clear errors are identified or when quantitative scales are fully ready for incorporation. I argue, as I have previously (Hyman 2007), for two significant kinds of change in the DSM-V: (a) the use of quantitative scales as alternatives or supplements to current qualitative criteria and $(b)$ reclustering of disorder families based on the most compelling current hypotheses about underlying neural circuits or genetics.

As discussed, for many domains of psychopathology, such as depression or ADHD, dimensional approaches will likely capture clinical and research data far more effectively than do current categorical approaches. An advantage of quantitative scales for clinical practice is that by facilitating the correlation of scores with distress, impairment, and risk of worsening psychopathology over time, dimensional approaches may provide a stronger basis for setting disorder thresholds and for making treatment decisions. One significant possibility is the development of dimensions that cut across domains of psychopathology. For example, a quantitative scale measuring depressed mood (or elevated mood) would be useful not only in the ultimate redefinition of mood disorders, but would be clinically useful for anxiety disorders, obsessive-compulsive spectrum disorders, and psychotic disorders where depression is often a fellow traveller. It is possible that well-constructed mood dimensions used along with anxiety and schizophrenia diagnoses could obviate the need to make multiple diagnoses or could confer clinical status on significant depressive symptomatology that does not rise to the level of major depression. Moreover, 
such an approach might ultimately permit the retirement of questionable categories such as schizoaffective disorder (Fraguas et al. 2007).

The development and testing of useful quantitative scales (e.g., for validity, reliability, and clinical utility) and the empirically based setting of diagnostic thresholds will not likely occur rapidly. As noted, it is fortunate that the DSM-V (Regier et al. 2009) and the ICD-11 will be treated as living documents to be updated as appropriate. Ideally, quantitative scales will be incorporated first in parallel to existing criteria, and ultimately as they are fully vetted in terms of biological plausibility, epidemiology, and clinical outcomes, they might replace some current categorical diagnoses. As research progresses, the initial scales, which will depend on clinical observation, may well be replaced with laboratory measures.

The second major change that I argue for is reclustering of current disorders according to the best current hypotheses about underlying neural circuitry or compelling genetic data $(\mathrm{Hy}-$ man 2007). Strong neurobiological or genetic data do not exist for all disorders within the DSM-IV, but for a number of major disorders, such data are convincing enough to suggest hypotheses about reaggregation of existing DSM-IV disorders into large groups, clusters, or spectra. Research, such as that which might be supported by the NIMH RDoC initiative, could focus on the cluster as a whole, rather than on the current diagnostic silos, and lead to a fresh bottom-up reanalysis. These reanalyses could be based on such approaches as epidemiology of symptom distribution and clustering in healthy and clinical populations, cognitive neuroscience and human neuroimaging in healthy and clinical populations (Hoekstra et al. 2007) or in healthy and ill twins or other family members (Brans et al. 2008, Cannon et al. 2002, Zainab et al. 2008). Also potentially useful would be studies of familial aggregation of symptoms clusters, segregation of symptoms across generations, studies to identify risk genes, and genetic or environmentally produced animal models. Such reanalyses of large clusters might yield useful clinically based symptom clusters that cohere in family studies, or cognitive or neurobiologically based findings that suggest new ways of dividing the cluster. These analyses could also yield clinically ascertained or laboratory-based dimensional measures that transgress the boundaries of current DSM-IV categorical disorders within the cluster. The reclustering itself would have little effect on current clinical practice, but could, with the encouragement of funding agencies and journal editors, help ultimately to facilitate the much needed deconstruction of reified diagnoses and encourage progress toward a new, more valid classification.

Examples of compelling neural circuitbased hypotheses that could organize large clusters include the fear-based anxiety disorders (amygdala-based fear circuitry disorders), the obsessive-compulsive disorder spectrum (fronto-striatal disorders), addictive and other impulse-control disorders (reward circuit disorders), and disorders of frontal circuits and executive functioning that might include ADHD. A psychosis cluster might be better organized today by shared genetic influences, given the vast unknowns about underlying neural circuits.

The fear-based anxiety disorders can serve as an example of this reclustering approach. This family of disorders is currently parsed by DSM-IV (Am. Psychiatr. Assoc. 1994) into generalized anxiety disorder, simple phobias, posttraumatic stress disorder, panic disorder, and social phobia. There is substantial comorbidity within this grouping and with depression (Kessler et al. 2005b, Moffit et al. 2007). Evidence for categorical separation among these disorders is not compelling. Imaging studies reveal some differences in regional brain activation to aversive stimuli but generally report shared hyperresponsiveness of the amygdala to innocuous stimuli and failure of the amygdala to exhibit normal desensitization when repeated aversive stimuli do not prove harmful. In addition, the prefrontal cortex fails to activate robustly across multiple disorders, thus failing to suppress abnormal amygdala 
activation (Etkin \& Wager 2007; Nitschke et al. 2009; Shin et al. 2004, 2005; Yehuda \& LeDoux 2007). Similar findings of excessive amygdala activation correlate with trait anxiety in healthy subjects (Etkin et al. 2004), suggesting that there may be no categorical separation from normalcy.

Lumping of the fear-based anxiety disorders, or alternatively, pairing generalized anxiety disorder with depression (Kendler et al. 1992) and clustering the remaining anxiety disorders, might provide a new opportunity for discovery of neural mechanisms, risk genes, and clinical observations. Cross-cutting dimensional definitions might be tested for validity and clinical utility. The results of such approaches are, of course, unpredictable. Nonetheless, hypothesis-driven reclustering or lumping of DSM-IV disorders according to neural circuit or genetic data followed by systematic reanalysis with modern tools may be the best way to escape the problem of reification without prematurely disrupting existing uses of DSM-IV.

Neither the development of quantitative dimensions nor agreement on reclustering (and thus a new table of contents for the DSM-V) will be easy. Nonetheless, to remain cognitive prisoners of an excessively specified, rigid categorical system based only on phenomenology would seem as untenable scientifically as it is clinically problematic. Epidemiology, genetics, psychology, and neuroscience have not been kind to the DSM-IV categories, nor have these reified categories been kind to science. The DSM-III was a brilliant advance that prioritized interrater reliability; now it is time to move on.

\section{SUMMARY POINTS}

1. DSM-III responded to a strong desire for interrater reliability by developing operationalized diagnostic criteria.

2. DSM-III and DSM-IV arbitrarily treat every disorder as a category discontinuous from normal and from other disorders and eschew quantitative or dimensional approaches to disorder descriptions.

3. DSM-III split large clusters of disorders, such as anxiety disorders, into a fairly large number of disorders that have arguably become reified: They are treated as if they were valid in most settings.

4. Evidence for excessive and scientifically premature splitting is the great degree of comorbidity among individuals with any DSM-IV diagnosis.

5. One result of promulgating highly specified operationalized criteria to describe heterogeneous disorders is that many patients meet no criteria and receive the diagnosis of Not Otherwise Specified (NOS).

6. Family and molecular genetic studies map very poorly onto strict DSM-IV disorder categories but help explicate the heterogeneity of clinical presentations.

7. Progress would seem to require seeing psychopathology afresh rather than through the lens of the DSM-IV. One way of accomplishing this is to establish new large groupings of disorders in the DSM-V based upon the most compelling current neurobiological and genetic hypotheses followed by bottom-up reanalysis.

8. It is also time, with due care, to introduce quantitative scales into the DSM-V. 


\section{DISCLOSURE STATEMENT}

The author is a member of the DSM-V Task Force and Chairs the International Advisory Group on the Revision of ICD-10, Chapter V. The author has provided consultation on early-stage drug discovery to Novartis and GlaxoSmithKline during the past three years, but accepts no compensation.

\section{ACKNOWLEDGMENT}

I have had the benefit of discussing my ideas at multiple conferences and meetings concerning the DSM and ICD classifications. This review represents my personal viewpoint and does not represent an official position of the DSM-V Task Force, of which I am a member, or of the International Advisory Group to the World Health Organization for the Revision of ICD-10, Chapter V (Mental and Behavioral Disorders), of which I am the Chair. Of course all errors and excesses are my own.

\section{LITERATURE CITED}

Am. Psychiatr. Assoc. 1980. Diagnostic and Statistical Manual of Mental Disorders. Washington, DC: Am. Psychiatr. Assoc. 3rd ed.

Am. Psychiatr. Assoc. 1987. Diagnostic and Statistical Manual of Mental Disorders. Washington, DC: Am. Psychiatr. Assoc. 3rd ed., rev.

Am. Psychiatr. Assoc. 1994. Diagnostic and Statistical Manual of Mental Disorders. Washington, DC: Am. Psychiatr. Assoc. 4th ed.

Am. Psychiatr. Assoc. 2000. Diagnostic and Statistical Manual of Mental Disorders. Washington, DC: Am. Psychiatr. Assoc. 4th ed., text rev.

Andrews G, Charney DS, Sirovatka PJ, Regier DA, eds. 2009. Stress-Induced and Fear Circuitry Disorders. Washington, DC: Am. Psychiatr. Assoc.

Andrews G, Slade T, Peters L. 1999. Classification in psychiatry: ICD-10 versus DSM-IV. Br. F. Psychiatry 174:3-5

Angold A, Erkanli A, Egger HL, Costello EJ. 2000. Stimulant treatment for children: a community perspective. 7. Am. Acad. Child Adolesc. Psychiatry 39:975-84

Baron-Cohen S, Belmonte MK. 2005. Autism: a window onto the development of the social and analytic brain. Annu. Rev. Neurosci. 28:109-126

Beck AT, Ward CH, Mendelson M, Mock JE, Erbaugh JK. 1962. Reliability of psychiatric diagnosis. 2. A study of consistency of clinical judgments and ratings. Am. F. Psychiatry 119:351-57

Berrettini WH. 2000. Are schizophrenic and bipolar disorders related? A review of family and molecular studies. Biol. Psychiatry 48:531-38

Bodmer W, Bonilla C. 2008. Common and rare variants in multifactorial susceptibility to common diseases. Nat. Genet. 6:695-701

Bowie CR, Reichenberg A, Patterson TL, Heaton PK, Harvey PD. 2006. Determinants of real-world functional performance in schizophrenia subjects: correlation with cognition, functional capacity, and symptoms. Am. 7. Psychiatry 163:418-25

Brans RGH, van Haren NEM, van Baal GCM, Schnack HG, Kahn RS, Hulshoff Pol HE. 2008. Heritability of changes in brain volume over time in twin pairs discordant for schizophrenia. Arch. Gen. Psychiatry 65:1259-68

Buchanan RW, Davis M, Goff D, Green MF, Keefe RSE, et al. 2005. A summary of the FDA-NIMHMATRICS Workshop on clinical trial design for neurocognitive drugs for schizophrenia. Schizophr. Bull. 31:5-19

Burton R. 1621. The Anatomy of Melancholy. Reprinted 2000. New York: N.Y. Rev. Book Classics 
Cannon TD, Thompson PM, van Erp TGM, Toga AW, Poutanen V-P, et al. 2002. Cortex mapping reveals regionally specific patterns of genetic and disease-specific gray-matter deficits in twins discordant for schizophrenia. Proc. Natl. Acad. Sci. USA 99:3228-33

Cardno AG, Rijsdijk FV, Sham PC, Murray RM, McGuffin P. 2002. A twin study of genetic relationships between psychotic symptoms. Am. 7. Psychiatry 159:539-45

Chobanian AV, Bakris GL, Black HR, Cushman WC, Green LA, et al. 2003. Seventh report of the Joint National Committee on Prevention, Detection, Evaluation, and Treatment of High Blood Pressure. Hypertension 42:1206-52

Clark LA, Watson D, Reynolds S. 1995. Diagnosis and classification of psychopathology: challenges to the current system and future directions. Annu. Rev. Psychol. 46:121-53

Cooper JE, Kendell RE, Gurland BJ, Sharpe L, Copeland JRM, Simon R. 1972. Psychiatric Diagnosis in New York and London: A Comparative Study of Hospital Admissions. New York: Oxford Univ. Press

Craddock N, O'Donovan MC, Owen MJ. 2005. The genetics of schizophrenia and bipolar disorder: dissecting psychosis. 7. Med. Genet. 42:193-204

Craddock N, O’Donovan MC, Owen MJ. 2006. Genes for schizophrenia and bipolar disorder? Implications for psychiatric nosology. Schizophr. Bull. 32:9-16

Crino R, Slade T, Andrews. 2005. The changing prevalence and severity of obsessive-compulsive disorder criteria from DSM-III to DSM-IV. Am. F. Psychiatry 162:876-82

Daiger SP, Browne SJ, Sullivan LS. 2007. Perspective on genes and mutations causing retinitis pigmentosa. Arch. Ophthalmol. 125:151-58

de Bruin EI, Ferdinand RF, Meester S, de Nijs PF, Verheij F. 2007. High rates of psychiatric co-morbidity in PDD-NOS. 7. Autism Dev. Disord. 37:877-86

Delgado MR, Nearing KI, Ledoux JE, Phelps EA. 2008. Neural circuitry underlying the regulation of conditioned fear and its relation to extinction. Neuron 59:829-38

Di Martino A, Shehzad A, Kelly C, Roy AK, et al. 2009. Relationship between cingulo-insular functional connectivity and autistic traits in neurotypical adults. Am. F. Psychiatry 166:891-99

Dunn CW, Hejnol A, Matus DQ, Pang K, Browne WE, et al. 2008. Broad phylogenomic sampling improves resolution of the animal tree of life. Nature 452:745-49

Etkin A, Klemenhagen KC, Dudman JT, Rogan MT, Hen R, et al. 2004. Individual differences in trait anxiety predict the response of the basolateral amygdala to unconsciously processed fearful faces. Neuron 44:1043-55

Etkin A, Wager TD. 2007. Functional neuroimaging of anxiety: a meta-analysis of emotional processing in PTSD, social anxiety disorder, and specific phobia. Am. 7. Psychiatry 164:1476-88

Fairburn CG, Bohn K. 2005. Eating disorder NOS (EDNOS): an example of the troublesome "not otherwise specified" (NOS) category in DSM-IV. Behav. Res. Ther. 43:691-701

Fanous A, Gardner C, Walsh D, Kendler KS. 2001. Relationship between positive and negative symptoms of schizophrenia and schizotypal symptoms in nonpsychotic relatives. Arch. Gen. Psychiatry 58:669-73

Feighner JP, Robins E, Guze SB, Woodruff RA Jr, Winokur G, Munoz R. 1972. Diagnostic criteria for use in psychiatric research. Arch. Gen. Psychiatry 26:57-63

Fekadu A, Kebede D, Alem A, Fekadu D, Mogga S, et al. 2006. Clinical outcome in bipolar disorder in a community-based follow-up study in Butajira, Ethiopia. Acta Psychiatr. Scand. 114:426-34

Ferreira MAR, O’Donovan MC, Ment YA, Jones IR, Rederfer DM, et al. 2008. Collaborative genome-wide association analysis supports a role for ANK3 and CACNA1C in bipolar disorder. Nat. Genet. 40:1056-58

Fischer BA, Carpenter WT Jr. 2009. Will the Kraepelinian dichotomy survive DSM-V? Neuropsychopharmacology 34:2081-87

Fraguas D, de Castro MJ, Medina O, Parellada M, Moreno D, et al. 2007. Does diagnostic classification of early-onset psychosis change over follow-up? Child Psychiatry Hum. Dev. 39:137-45

Freitag CM. 2007. The genetics of autistic disorders and its clinical relevance: a review of the literature. Mol. Psychiatry 12:2-22

Galanter CA, Leibenluft E. 2008. Frontiers between attention deficit hyperactivity disorder and bipolar disorder. Child Adolesc. Psychiatr. Clin. N. Am. 17:325-46

Goldstein S, Schwebach AJ. 2004. The comorbidity of pervasive developmental disorder and attention deficit hyperactivity disorder: results of a retrospective chart review. F. Autism Dev. Disord. 34:329-39

Methodologically strong study analyzing the relationship between neural structure, genetics, and disease processes using twin pairs discordant for schizophrenia. 
Although the complex result may not fully stand up, it forcefully demonstrates shared genes involved in schizophrenia and bipolar disorder.

Classic paper clarifying the problem of validity in diagnosis of mental disorders.
Green EK, Raybould R, Macgregor S, Gordon-Smith K, Heron J, et al. 2005. Operation of the schizophrenia susceptibility gene, neuregulin 1 , across traditional diagnostic boundaries to increase risk for bipolar disorder. Arch. Gen. Psychiatry 62:642-48

Green MF. 1996. What are the functional consequences of neurocognitive deficits in schizophrenia? Am. F. Psychiatry 153:321-30

Grundy SM, Cleeman KO, Merz CNB, Brewer HB Jr, Clark LT, et al. 2004. Implications of recent clinical trials for the National Cholesterol Education Program Adult Treatment Panel III Guidelines. Circulation 110:227-39

Happe F, Ronald A, Plomin R. 2006. Time to give up on a single explanation for autism. Nat. Neurosci. 91218-20

Healy D. 2006. The latest mania: selling bipolar disorder. PLoS Med. 3:e185

Hoekstra RA, Bartels M, Verweij CJ, Boomsma DI. 2007. Heritability of autistic traits in the general population. Arch. Pediatr. Adolesc. Med. 161:372-77

Howland RH, Rush AJ, Wisniewski SR, Trivedi MH, Warden D, et al. 2009. Concurrent anxiety and substance use disorders among outpatients with major depression: clinical features and effect on treatment outcome. Drug Alcohol Depend. 99:248-60

Hudziak JJ, Kerks EM, Althoff RR, Rettew DC, Boomsma DI. 2005. The genetic and environmental contributions to attention deficit hyperactivity disorder as measured by the Conners' rating scales-revised. $\mathrm{Am}$. 7. Psychiatry 162:1614-20

Hunter DJ, Altshuler D, Rader DJ. 2008. From Darwin's finches to canaries in the coal mine: mining the genome for new biology. N. Engl. 7. Med. 358:2760-63

Hyman SE. 2007. Can neuroscience be integrated into the DSM-V? Nat. Rev. Neurosci. 8:725-32

Hyman SE. 2008. A glimmer of light for neuropsychiatric disorders. Nature 458:890-93

Hyman SE, Fenton WS. 2003. What are the right targets for psychopharmacology? Science 299:350-51

Hyman SE, Malenka RC, Nestler EJ. 2006. Neural mechanisms of addiction: the role of reward-related learning and memory. Annu. Rev. Neurosci. 29:565-98

Int. Schizophr. Consort. 2008. Rare chromosomal deletions and duplications increase risk of schizophrenia. Nature 455:237-41

Int. Schizophr. Consort. 2009. Common polygenic variation contributes to risk of schizophrenia and bipolar disorder. Nature 460:748-52

Jackson JL, Passamonti M, Kroenke K. 2007. Outcome and impact of mental disorders in primary care at 5 years. Psychosom. Med. 69:270-76

Jablensky A, Sartorius N, Ernberg G, Anker M, Korten A, et al. 1992. Schizophrenia: manifestations, incidence and course in different cultures. A World Health Organization ten-country study. Psychol. Med. Monogr. Suppl. 20:1-97

Keefe RSE, Bilder RM, Davis SM, Harvey PD, Palmer BW, et al. 2007. Neurocognitive effects of antipsychotic medications in patients with chronic schizophrenia in the CATIE trial. Arch. Gen. Psychiatry 64:633-47

Keller MB, Lavori PW, Endicott J, Coryell W, Klerman GL. 1983. "Double depression”: two-year follow-up. Am. 7. Psychiatry 140:689-94

Kendell R, Jablensky A. 2003. Distinguishing between validity and utility of psychiatric diagnoses. Am. F. Psychiatry 160:4-12

Kendler KS. 2001. Twin studies of psychiatric illness. Arch. Gen. Psychiatry 58:1005-14

Kendler KS, Davis CG, Kessler RC. 1997. The familial aggregation of common psychiatric and substance use disorders in the National Comorbidity Survey: a family history study. Br. F. Psychiatry 170:541-48

Kendler KS, Gardner CO Jr. 1998. Boundaries of major depression: an evaluation of DSM-IV criteria. Am. 7. Psychiatry 155:172-77

Kendler KS, Neale MC, Kessler RC, Heath AC, Eaves LJ. 1992. Major depression and generalized anxiety disorder. Same genes, (partly) different environments? Arch. Gen. Psychiatry 49:716-22

Kessler RC, Berglund P, Demler O, Jin R, Merikangas KR, Walters EE. 2005a. Lifetime prevalence and age-of-onset distributions of DSM-IV disorders in the National Comorbidity Survey Replication. Arch. Gen. Psychiatry 62:593-602 
Kessler RC, Chiu WT, Demler O, Merikangas KR, Walters EE. 2005b. Prevalence, severity, and comorbidity of 12-month DSM-IV disorders in the National Comorbidity Survey Replication. Arch. Gen. Psychiatry 62:617-27

Kessler RC, Nelson CB, McGonagle KA, Liu J, Swartz M, Blazer DG. 1996. Comorbidity of DSM-III-R major depressive disorder in the general population; results from the US National Comorbidity Survey. Br. 7. Psychiatry 168(Suppl. 30):17-30

Kety SS, Rosenthal D, Wender PH, Schulsinger F. 1971. Mental illness in the biological and adoptive families of adopted schizophrenics. Am. F. Psychiatry 128:302-6

Kilipinen H, Ylisaukko-oja T, Hennah W, Palo OM, Verilo T, et al. 2008. Association of DISC1 with autism and Asperger syndrome. Mol. Psychiatry 13:187-96

Kraepelin E. 1899. Psychiatry: A Textbook for Students and Physicians. Transl. 1991, ed. H Metoui, S Ayed. Canton, MA: Watson Publ.

Kreuger RF, Markon KE. 2006. Reinterpreting comorbidity: a model-based approach to understanding and classifying psychopathology. Annu. Rev. Clin. Psychol. 2:111-33

Lane C. 2007. Shyness: How Normal Behavior Became a Sickness. New Haven, CT: Yale Univ. Press

Laursen TM, Labouriau R, Licht RW, Bertelsen A, Munk-Olsen T, Mortensen PB. 2005. Family history of psychiatric illness as a risk factor for schizoaffective disorder: a Danish register-based cohort study. Arch. Gen. Psychiatry 62:841-48

Leucht S, McGrath J, Kissling W. 2003. Lithium for schizophrenia. Cocbrane Database Syst. Rev. 3:CD003834

Lichtenstein P, Yip BH, Bjork C, Pawitan Y, Cannon TD, et al. 2009. Common genetic determinants of schizophrenia and bipolar disorder in Swedish nuclear families: a population-based study. Lancet 373:234 39

Losh M, Adolphs R, Poe M, Couture S, Penn D, et al. 2009. Neuropsychological profile of autism and the broad autism phenotype. Arch. Gen. Psychiatry 66:518-26

Malhi GS, Green M, Fagiolini A, Peselow ED, Kumari V. 2008. Schizoaffective disorder: diagnostic issues and future recommendations. Bipolar Disord. 10(1 Pt. 2):215-30

Mao Y, Ge X, Frank CL, Madison JM, Koehler AN, et al. 2009. Disrupted in schizophrenia 1 regulates neuronal progenitor proliferation via modulation of GSK3beta/beta-catenin signaling. Cell 136:1017-31

Mataix-Cols D, Rosario-Campos MC, Leckman JF. 2005. A multidimensional model of obsessive-compulsive disorder. Am. F. Psycbiatry 162:2193-94

Matsunaga H, Maebayashi K, Hayashida K, Okino K, Matsui T, et al. 2008. Symptom structure in Japanese patients with obsessive-compulsive disorder. Am. F. Psychiatry 165:251-53

McGlashan TH, Grilo CM, Skodol AE, Gunderson JG, Shea MT, et al. 2000. The Collaborative Longitudinal Personality Disorders Study: baseline Axis I/II and II/II diagnostic co-occurrence. Acta Psychiatr. Scand. 102:256-64

Merikangas KR, Risch N. 2003. Genomic priorities and public health. Science 302:599-601

Millar JK, Wilson-Annan JC, Anderson S, Christie S, Taylor MS, et al. 2000. Disruption of two novel genes by a translocation cosegregating with schizophrenia. Hum. Mol. Gen. 9:1415-23

Mineka S, Watson D, Clark LA. 1998. Comorbidity of anxiety and unipolar mood disorders. Annu. Rev. Psychol. 49:377-412

Moffitt TE, Harrington H, Caspi A, Kim-Cohen J, Milne BJ, et al. 2007. Depression and generalized anxiety disorder: cumulative and sequential comorbidity in a birth cohort followed prospectively to age 32 years. Arch. Gen. Psychiatry 64:651-60

Morrow EM, Yoo S-Y, Flavell SW, Kim T-K, Lin Y, et al. 2008. Identifying autism loci and genes by tracing recent shared ancestry. Science 321:218-23

Morse SJ. 2004. New neuroscience, old problems: legal implications of brain science. Cerebrum 6:81-90

New AS, Triebwasser J, Charney DS. 2008. The case for shifting borderline personality disorder to Axis I. Biol. Psychiatry 64:653-59

Nitschke JB, Srainopoulos I, Oathes D, Johnstone T, Whalen PJ, et al. 2009. Anticipatory activation in the amygdala and anterior cingulate in generalized anxiety disorder and prediction of treatment response. Am. F. Psycbiatry 166:302-10

O'Donovan MC, Craddock N, Norton N, et al. 2008. Identification of loci associated with schizophrenia by genome-wide association and follow-up. Nat. Genet. 40:1053-55 
One of the most influential papers in the history of research on mental illness; the precursor of DSM-III.

Large practical trial that demonstrates the inapplicability of pure types (in depression) to real world clinical populations.

A very simple, small study demonstrating that if operationalized criteria are used, small wording differences lead to significant differences in individuals defined as ill.

This report led to the discovery of the important candidate gene, DISC-1, which is associated with multiple disorders that cross DSM-IV diagnostic boundaries.
Pacione LR, Szego MJ, Ikeda S, Nishina PM, McInnes RR. 2003. Progress toward understanding the genetic and biochemical mechanisms of inherited photoreceptor degenerations. Annu. Rev. Neurosci. 26:657-700

Pallanti S, Hollander E. 2008. Obsessive-compulsive disorder spectrum as a scientific "metaphor." CNS Spectr. 13(9 Suppl.):6-15

Pope HG Jr, Lipinski JF Jr. 1978. Diagnosis in schizophrenia and manic-depressive illness: a reassessment of the specificity of "schizophrenic" symptoms in the light of current research. Arch. Gen. Psychiatry 35:11-28

Pope HG Jr, Lipinski JF, Cohen BM, Axelrod DT. 1980. "Schizoaffective disorder": an invalid diagnosis? A comparison of schizoaffective disorder, schizophrenia, and affective disorder. Am. F. Psychiatry 137:921-27

Rauch SL, Shin LM, Phelps EA. 2006. Neurocircuitry models of posttraumatic stress disorder and extinction: human neuroimaging research—past, present, and future. Biol. Psychiatry 60:376-82

Regier DA, Farmer ME, Rae DS, Locke BL, Keith SJ, et al. 1990. Comorbidity of mental disorders with alcohol and other drug abuse: results from the Epidemiologic Catchment Area (ECA) Study. $7 A M A$ 264:2511-18

Regier DA, Narrow WE, Kul EA, Kupfer DJ. 2009. The conceptual development of DSM-V.Am. F. Psychiatry 166:645-50

Robins E, Guze SB. 1970. Establishment of diagnostic validity in psychiatric illness: its application to schizophrenia. Am. F. Psychiatry 126:983-87

Robins LN. 1994. How recognizing “comorbidities” in psychopathology may lead to an improved research nosology. Clin. Psychol. Sci. Pract. 1:93-95

Rush AJ, Trivedi MH, Wisniewski SR, Nierenberg AA, Stewart JW, et al. 2006. Acute and longer-term outcomes in depressed outpatients requiring one or several treatment steps: a STAR*D report. Am. F. Psychiatry 163:1905-17

Sartorius N. 2009. Disability and mental illness are different entities and should be assessed separately. World Psychiatry 8:86

Shankman SA, Lewinsohn PM, Klein DN, Small JW, Seeley JR, Altman SE. 2009. Subthreshold conditions as precursors for full syndrome disorders: a 15-year longitudinal study of multiple diagnostic classes. 7. Child Psychol. Psychiatry 50:1485-94

Shaw P, Eckstrand K, Sharp W, Blumenthal J, Lerch JP, et al. 2007. Attention-deficit/hyperactivity disorder is characterized by a delay in cortical maturation. Proc. Natl. Acad. Sci. USA 104:19649-54

Shi J, Levinson DF, Duan J, Sanders AR, Zheng Y, et al. 2009. Common variants on chromosome 6p22.1 are associated with schizophrenia. Nature 460:753-57

Shin LM, Orr SP, Carson MA, Cheon B, Solomon J, et al. 2004. Regional cerebral blood flow in the amygdala and medial prefrontal cortex during traumatic imagery in male and female Vietnam veterans with PTSD. Arch. Gen. Psychiatry 61:168-76

Shin LM, Wright CI, Cannistraro PA, Wedig MM, McMullin K, et al. 2005. A functional magnetic resonance imaging study of amygdala and medial prefrontal cortex responses to overtly presented fearful faces in posttraumatic stress disorder. Arch. Gen. Psychiatry 62:273-81

Siever LJ, Davis K. 1991. A psychobiological perspective on the personality disorders. Am. 7. Psychiatry 148:1647-58

Sigvardsson S, Bohman M, Cloninger CR. 1996. Replication of the Stockholm Adoption Study of Alcoholism. Confirmatory cross-fostering analysis. Arch. Gen. Psychiatry 53:681-87

Skodol AE, Gunderson JG, Pfohl B, Widiger TA, Livesley WJ, Siever LJ. 2002. The borderline diagnosis I: psychopathology, comorbidity, and personality structure. Biol. Psychiatry 51:936-50

Skodol AE, Siever LJ, Livesley WJ, Gunderson JG, Pfohl B, Widiger TA. 2002. The borderline diagnosis II: biology, genetics, and clinical course. Biol. Psychiatry 51:951-63

Slade T, Andrews G. 2001. DSM-IV and ICD-10 generalized anxiety disorder: discrepant diagnoses and associated disability. Soc. Psychiatry Psychiatr. Epidemiol. 36:45-51

St. Clair D, Blackwood D, Muir W, Carothers A, Walker M, et al. 1990. Association within a family of a balanced autosomal translocation with major mental illness. Lancet 336:13-16

Spitzer RL, Endicott J, Robins E. 1975. Research diagnostic criteria. Psychopharmacol. Bull. 11:22-25

Tan HY, Sust S, BuckholtzJW, Mattay VS, Meyer-Lindengerg A, et al. 2006. Dysfunctional prefrontal regional specialization and compensation in schizophrenia. Am. 7. Psychiatry 163:1967-77 
Verheul R, Bartak A, Widiger T. 2007. Prevalence and construct validity of personality disorder not otherwise specified (PDNOS). 7. Personal. Disord. 21:359-70

Wakabayashi A, Baron-Cohen S, Uchiyama T, Yoshida Y, Kuroda M, Wheelwright S. 2007. Empathizing and systemizing in adults with and without autism spectrum conditions: cross-cultural stability. F. Autism Dev. Disord. 37:1823-32

Walsh CA, Morrow EM, Rubenstein JLR. 2008. Autism and brain development. Cell 135:396-400

Walsh T, McClellan JM, McCarthy SE, Addington AM, Pierce SB, et al. 2008. Rare structural variants disrupt multiple genes in neurodevelopmental pathways in schizophrenia. Science 320:539-43

Weiss LA, Shen Y, Korn JM, Arking EE, Miller DT, et al. 2008. Association between microdeletion and microduplication at 16p11.2 and autism. N. Engl. F. Med. 358:667-75

Widiger TA, Clark LA. 2000. Toward DSM-V and the classification of psychopathology. Psychol. Bull. 126:94663

Widiger TA, Mullins-Sweatt SN. 2009. Five-factor model of personality disorder: a proposal for DSM-V. Anпu. Rev. Clin. Psychol. 5:197-220

Widiger TA, Trull TJ.2007. Plate tectonics in the classification of personality disorder: shifting to a dimensional model. Am. Psychol. 62:71-83

World Health Org. 1977. The ICD-10 Classification of Mental and Behavioural Disorders. Geneva: World Health Org.

World Health Org. 1992. The ICD-10 Classification of Mental and Behavioural Disorders. Geneva: World Health Org.

Xu B, Roos JL, Levy S, van Rensburg EJ, Gogos JA, Karayiorgou M. 2008. Strong association of de novo copy number mutations with sporadic schizophrenia. Nat. Genet. 40:880-85

Yehuda R, LeDoux J. 2007. Response variation following trauma: a translational neuroscience approach to understanding PTSD. Neuron 56:19-32

Zainab D, Csernansky JG, Barch DM. 2008. Prefrontal cortex function in nonpsychotic siblings of individuals with schizophrenia. Biol. Psychiatry 63:490-97

Zeggini E, Scott LJ, Saxens T, Voight BF, Marchini JL, et al. 2008. Meta-analysis of genome-wide association data and large-scale replication identifies additional susceptibility loci for type 2 diabetes. Nat. Genet. 40:638-45 
Annual Review of Clinical Psychology

Volume 6, 2010

\section{Contents}

Personality Assessment from the Nineteenth to Early Twenty-First

Century: Past Achievements and Contemporary Challenges

Fames N. Butcher

1

Prescriptive Authority for Psychologists

Robert E. McGrath

The Admissibility of Behavioral Science Evidence in the Courtroom:

The Translation of Legal to Scientific Concepts and Back

David Faust, Paul W. Grimm, David C. Abern, and Mark Sokolik

Advances in Analysis of Longitudinal Data

Robert D. Gibbons, Donald Hedeker, and Stephen DuToit

Group-Based Trajectory Modeling in Clinical Research

Daniel S. Nagin and Candice L. Odgers

Measurement of Functional Capacity: A New Approach to

Understanding Functional Differences and Real-World Behavioral

Adaptation in Those with Mental Illness

Thomas L. Patterson and Brent T. Mausbach

The Diagnosis of Mental Disorders: The Problem of Reification

Steven E. Hyman

Prevention of Major Depression

Ricardo F. Muñoz, Pim Cuijpers, Filip Smit, Alinne Z. Barrera, and Yan Leykin

Issues and Challenges in the Design of Culturally Adapted

Evidence-Based Interventions

Felipe González Castro, Manuel Barrera 7r., and Lori K. Holleran Steiker

Treatment of Panic

Norman B. Schmidt and Meghan E. Keough

Psychological Approaches to Origins and Treatments of Somatoform

Disorders

Michael Witthöft and Wolfgang Hiller 
Cognition and Depression: Current Status and Future Directions

Ian H. Gotlib and Futta Foorman

The Genetics of Mood Disorders

Jennifer Y.F. Lau and Thalia C. Eley

Self-Injury

Matthew K. Nock

Substance Use in Adolescence and Psychosis: Clarifying the

Relationship

Emma Barkus and Robin M. Murray

Systematic Reviews of Categorical Versus Continuum Models in

Psychosis: Evidence for Discontinuous Subpopulations Underlying

a Psychometric Continuum. Implications for DSM-V, DSM-VI, and DSM-VII

Richard 7. Linscott and Fim van Os

Pathological Narcissism and Narcissistic Personality Disorder

Aaron L. Pincus and Mark R. Lukowitsky....

Behavioral Treatments in Autism Spectrum Disorder:

What Do We Know?

Laurie A. Vismara and Sally 7. Rogers

Clinical Implications of Traumatic Stress from Birth to Age Five

Ann T. Chu and Alicia F. Lieberman

Emotion-Related Self-Regulation and Its Relation to Children's Maladjustment

Nancy Eisenberg, Tracy L. Spinrad, and Natalie D. Eggum

Successful Aging: Focus on Cognitive and Emotional Health

Colin Depp, Ipsit V. Vabia, and Dilip Feste

Implicit Cognition and Addiction: A Tool for Explaining Paradoxical

Behavior

Alan W. Stacy and Rineout W. Wiers

Substance Use Disorders: Realizing the Promise of Pharmacogenomics and Personalized Medicine

Kent E. Hutchison

Update on Harm-Reduction Policy and Intervention Research

G. Alan Marlatt and Katie Witkiewitz...

Violence and Women's Mental Health: The Impact of Physical, Sexual, and Psychological Aggression

Carol E. Fordan, Rebecca Campbell, and Diane Follingstad 